\title{
Ultrasound-Assisted Synthesis of Isatin-Type 5'-(4-Alkyl/Aryl-1H-1,2,3-triazoles) via 1,3-Dipolar Cycloaddition Reactions
}

\author{
Bianca N. M. Silva, ${ }^{a}$ Angelo C. Pinto,${ }^{a, \dagger}{ }^{\dagger}$ Fernando C. Silva,${ }^{b}$ Vitor F. Ferreira ${ }^{b}$ and \\ Bárbara V. Silva*a \\ ${ }^{a}$ Instituto de Química, Universidade Federal do Rio de Janeiro, 21949-900 Rio de Janeiro-RJ, Brazil \\ ${ }^{b}$ Instituto de Química, Universidade Federal Fluminense, 24020-141 Niterói-RJ, Brazil
}

\begin{abstract}
This short report describes the preparation of twelve isatin derivatives, 5' -(4-alkyl/aryl-1H1,2,3-triazoles), using 5-azido-spiro[1,3-dioxolane-2,3'-indol]-2' (1' $H)$-one in the presence of various alkynes under acidic conditions and ultrasound irradiation. Compared with conventional methods, yields increased to $78-98 \%$, and reaction times decreased to $5 \mathrm{~min}$. Besides time and energy saving, there was no need for purification of the product by column chromatography on silica gel, generating less waste and spent solvent.
\end{abstract}

Keywords: isatin, 1H-1,2,3-triazoles, 1,3-dipolar cycloaddition reactions, ultrasound irradiation

\section{Introduction}

Isatin is a multifunctional heterocyclic compound employed in obtaining a large number of compounds of pharmacological interest. Its structure allows for electrophilic substitution reactions of the aromatic ring, acylating or alkylating the $\mathrm{NH}$ group, and the selective reduction or condensation in two chemically distinct carbonyls. ${ }^{1-7}$

The 1,3-dipolar cycloaddition reaction between the regioselective organic azides and the terminal alkynes catalyzed by copper(I) is currently the most commonly used method for obtaining $1 H$-1,2,3-triazoles, which are heterocycles of exclusively synthetic origin. ${ }^{8}$ This class of compounds also has several applications in medicinal chemistry. ${ }^{9-11}$

Our research group recently published the synthesis of $1 H$-1,2,3-triazoles containing isatin nuclei via different terminal alkynes. ${ }^{12}$ However, advances related to the use of ultrasound in organic synthesis aroused our attention.

Ultrasound irradiation has been considered a clean and useful method in organic synthesis. Compared with traditional methods, ultrasound-assisted organic synthesis features short reaction times, high yields and mild conditions. In addition, ultrasound irradiation follows the

*e-mail: barbara.iq@gmail.com

This paper is dedicated to the memory of our wonderful Professor Angelo da Cunha Pinto, who recently passed away. sixth principle of green chemistry, which proposes the pursuit of energy efficiency. ${ }^{13,14}$

\section{Experimental}

General procedure for preparation of 5'-(4-alkyl/aryl-1H1,2,3-triazole)-isatin (2a-2I) through ultrasound

A mixture of $2.64 \mathrm{mmol}$ of 5-azido-spiro[1,3-dioxolane2,3'-indol]-2'(1' $H$ )-one, $3.17 \mathrm{mmol}$ of the alkyne (see Scheme 1), $0.19 \mathrm{mmol}$ of $\mathrm{CuSO}_{4} .5 \mathrm{H}_{2} \mathrm{O}$, an excess of sodium ascorbate (AscNa, $0.42 \mathrm{mmol}$ ), $0.87 \mathrm{mmol}$ (30 mol\% based on 2) of acetic acid and an equal amount of tert-butanol and water (2.24 $\mathrm{mL}$ ) was subjected to ultrasound (Branson 1510DTH) irradiation for 5 minutes. After this period, a liquid-liquid extraction was performed with ethyl acetate and water. The organic layer was dried with anhydrous sodium sulfate and filtered, and the solvent was evaporated under reduced pressure. The yields are shown in Table 1.

\section{Results and Discussion}

Initially, the nitration reaction of isatin ${ }^{15}$ was performed, and the ketal dioxolane of 5-nitro-isatin was prepared from 5-nitro-isatin using ethylene glycol and $p$ - $\mathrm{TsOH}$ in toluene. Then, the nitro group was reduced by catalytic hydrogenation to give the ketal dioxolane of 5-amine-isatin.

In the next step, the azido group was obtained by a 


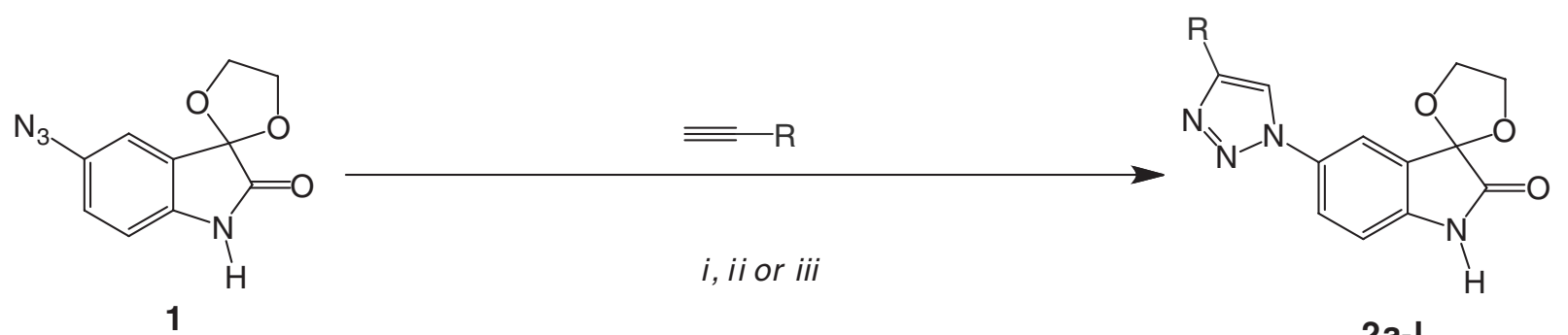

(i) $\mathrm{CuSO}_{4} \cdot 5 \mathrm{H}_{2} \mathrm{O}$, AscNa, (excess) $\mathrm{H}_{2} \mathrm{O}: \mathrm{CH}_{2} \mathrm{Cl}_{2}$ (1:1), rt, $48 \mathrm{~h}$; (ii) $\mathrm{CuSO}_{4} \cdot 5 \mathrm{H}_{2} \mathrm{O}$, AscNa (excess) $\mathrm{AcOH}$, $\mathrm{H}_{2} \mathrm{O}$ :tert-BuOH (1:1), rt, $24 \mathrm{~h}$ or (iii) $\mathrm{CuSO}_{4} .5 \mathrm{H}_{2} \mathrm{O}$, AscNa (excess) $\mathrm{AcOH}, \mathrm{H}_{2} \mathrm{O}$ :tert-BuOH (1:1), rt., ))), 5 min Scheme 1. Synthesis of 5'-(4-alkyl/aryl-1H-1,2,3-triazoles) under various conditions.

diazotization reaction with sodium nitrite in an acidic medium, with the subsequent addition of $\mathrm{NaN}_{3}$ generating the 5-azido-spiro[1,3-dioxolane-2,3'-indol]-2'(1'H)-one. The synthesis of these molecules has been described recently by our research group. ${ }^{12}$

The 5'-(4-alkyl/aryl-1H-1,2,3-triazole)-isatins (2a-2l) were obtained through 5-azido-spiro[1,3-dioxolane-2,3'indol]-2' $\left(1^{\prime} H\right)$-one (1) using a treatment of the terminal alkynes with $\mathrm{CuSO}_{4} .5 \mathrm{H}_{2} \mathrm{O}$ and sodium ascorbate (AscNa) in the presence of acetic acid as a catalyst and ultrasonic irradiation (method iii, Scheme 1). The results with and without acetic acid (methods ii and iii) were previously published and are also shown in Table 1 for the purpose of comparison.

Preliminary studies of the reaction of the 5-azidospiro[1,3-dioxolane-2,3'-indol]-2'(1'H)-one with terminal alkynes were performed using $\mathrm{CuSO}_{4} \cdot 5 \mathrm{H}_{2} \mathrm{O}, \mathrm{AscNa}$ and a mixture of $\mathrm{H}_{2} \mathrm{O}: \mathrm{CH}_{2} \mathrm{Cl}_{2}(1: 1)$ as the solvent (method $i$, Scheme 1). In this method, thin layer chromatography (TLC) was used to confirm that there was no overall

Table 1. The triazole yields through conventional methods without acetic acid ( $\mathrm{AcOH})$, with $\mathrm{AcOH}$ and under ultrasound irradiation

\begin{tabular}{|c|c|c|c|}
\hline \multirow[b]{2}{*}{ Compound $(\mathrm{R}=)$} & \multicolumn{3}{|c|}{ Yield /\% } \\
\hline & $\begin{array}{l}\text { Conventional method } \\
(48 \mathrm{~h})\end{array}$ & $\begin{array}{l}\text { Conventional method with } \\
\text { AcOH cat. }(24 \text { h) }\end{array}$ & $\begin{array}{l}\text { Ultrasound } \\
\text { (5 min) }\end{array}$ \\
\hline & - & 60 & 95 \\
\hline & 32 & 66 & 78 \\
\hline & 25 & 56 & 82 \\
\hline & 13 & 55 & 92 \\
\hline
\end{tabular}


Table 1. The triazole yields through conventional methods without acetic acid (AcOH), with $\mathrm{AcOH}$ and under ultrasound irradiation (cont.)

\begin{tabular}{|c|c|c|c|}
\hline \multirow{4}{*}{ Compound $(\mathrm{R}=)$} & \multicolumn{3}{|c|}{ Yield / \% } \\
\hline & $\begin{array}{c}\text { Conventional method } \\
(48 \mathrm{~h})\end{array}$ & $\begin{array}{l}\text { Conventional method with } \\
\text { AcOH cat. }(24 \mathrm{~h})\end{array}$ & $\begin{array}{l}\text { Ultrasound } \\
\text { (5 min) }\end{array}$ \\
\hline & 31 & 68 & 83 \\
\hline & 26 & 70 & 88 \\
\hline
\end{tabular}

(1)

(1)


consumption of $\mathbf{1}$, and flash column chromatography was used to isolate the resulting byproduct.

Even though the byproduct of the structure has not been fully identified in our investigation, it is noteworthy that Sharpless and co-authors ${ }^{16}$ observed the formation of dimers (bis-triazoles, 5-hydroxytriazoles and diacetylenes) as undesired byproducts in the click reaction. The triazole derivatives were obtained in yields below $30 \%$ (Table 1).

In addition to low yields, the use of a chromatography column is not considered environmentally friendly because of the large amount of solvent used (approximately $4 \mathrm{~L}$ of ethyl acetate and $4 \mathrm{~L}$ hexane for each substance). Notably, in these conditions the reagents were not completely soluble in the reaction medium. Some researchers emphasize that there is no need for the species involved in the reaction to fully dissolve in the medium provided that the samples are kept under strong agitation. ${ }^{17}$

Aiming at improving the product yields in the first method, the $\mathrm{CH}_{2} \mathrm{Cl}_{2}$ was replaced with tert-butanol, and excess alkyne was added with a catalytic amount of $\mathrm{AcOH}$, leading to a good yield in the 2a-2l products (method ii, Scheme 1 and Table 1) without requiring further purification using column chromatography.

As shown in Table 1, we have observed that the reaction time for the synthesis of triazoles was influenced by the presence of $\mathrm{AcOH}$. In this condition, the reaction time was reduced from 48 to 24 hours. ${ }^{18}$

In general, reactions performed under ultrasound irradiation have higher yields and better selectivities than those carried out under classical conditions (shaking, heating, cooling). Furthermore, the reaction time is greatly reduced.

Indeed, the use of ultrasound produced 5'-(4-alkyl/aryl$1 H-1,2,3$-triazoles) in higher yields than the observed for methods $i$ and $i i$, and the reaction time was only 5 minutes. How the ultrasound irradiation affects the reaction is still a subject of much debate in the scientific community. There are two phenomena involved in ultrasound-mediated reactions that can be analyzed separately to gain a better understanding: the physical phenomenon and the chemical phenomenon. ${ }^{19,20}$ The physical phenomenon can be divided into three types: the first refers to the sonic pressure, which subjects the liquid compression and rarefaction; the second is cavitation, which is the collapse of microbubbles of a liquid formed by ultrasonic energy; and the third is a phenomenon related to mass transport resulting from turbulent mixing and acoustic agitation.

A chemical phenomenon bound to a physical phenomenon primarily is a result of the cavitation effect of changes in the temperature and pressure of the reaction medium, and in this case, the reactivities of the substances involved in the reaction are increased. However, it is believed that the propagation of ultrasound can facilitate the interaction at various stages and the migration of the nucleophile into the organic phase, making it easier to attack. $^{21,22}$

Few investigations have focused on the effects of the substituents on the reactivity of the substrates involved in the reaction of 1,3-dipolar cycloaddition, especially using the click reaction. However, generally speaking, alkynes ${ }^{23}$ and azides ${ }^{24}$ containing electron-withdrawing groups (EWG) are less bulky and more reactive. Thus, Feldman et $a l .{ }^{25}$ reported that primary and secondary azides react selectively with phenyl acetylene, and no product was observed when tertiary azides were used.

\section{Conclusions}

In summary, we investigated three methods for the synthesis of a series of isatin-type 5'-(4-alkyl/aryl-1H1,2,3-triazoles) from organic azides and terminal alkynes. Acetic acid combined with ultrasonic irradiation was shown to play a key role in the click reaction, providing triazoles-isatins quickly and efficiently. All the products are obtained in just $5 \mathrm{~min}$ without purification step, saving time, reducing energy and wastes, featuring an environmentally friendly method.

The ultrasound effects influencing the reaction are not well understood; however, using ultrasound, triazoles were obtained approximately 300 times faster than by other methods. The nature of the substituent had no significant influence on the reactivity of the alkyne. Although an acidic medium was used, the dehydration of the alkynes with a hydroxyl group was not observed.

\section{Supplementary Information}

Supplementary information associated with this work (NMR spectra $\left({ }^{1} \mathrm{H}\right.$ and $\left.{ }^{13} \mathrm{C}\right)$, infrared and EMAR-ESI $(+)$ : $\left.[\mathrm{M}+\mathrm{H}]^{+}\right)$is available in reference 12 .

\section{Acknowledgments}

The authors thank the Brazilian agencies National Counsel for Technological and Scientific Development (CNPq), State of Rio de Janeiro Research Foundation (FAPERJ) and Coordination for the Improvement of Higher Education Personnel (CAPES).

\section{References}

1. Garden, S. J.; Torres, J. C.; Ferreira, A. A.; Silva, R. B.; Pinto, A. C.; Tetrahedron Lett. 1997, 38, 1501. 
2. Silva, J. M.; Garden, S. J.; Pinto, A. C.; J. Braz. Chem. Soc. 2001, 12, 273.

3. Silva, B. V.; J. Braz. Chem. Soc. 2013, 24, 707.

4. Garden, S. J.; Côrrea, M. B.; Pinto, A. C.; Tetrahedron Lett. 2003, 44, 7617.

5. Luppi, G.; Monari, M.; Côrrea, R. J.; Violante, F. A.; Pinto, A. C.; Kaptein, B.; Broxterman, Q. B.; Garden, S. J.; Tomasini, C.; Tetrahedron 2006, 62, 12017.

6. Boechat, N.; Kover, W. B.; Bastos, M. M.; Pinto, A. C.; Maciel, L. C.; Mayer, L. M. U.; Silva, F. S. Q.; Sá, P. M.; Mendonça, J. S.; Wardell, S. M. S. V.; Arruda, M. S. L.; J. Braz. Chem. Soc. 2008, 19, 445.

7. Schmidt, M. S.; Perillo, I. A.; González, M.; Blanco, M. M.; Tetrahedron Lett. 2012, 53, 2514.

8. Medal, M.; Tørnoe, C. W.; Chem. Rev. 2008, 108, 2952.

9. Uzgören-Baran, A.; Tel, B. C.; Sarigöl, D.; Öztürk, E. I.; Kazkayasi, I.; Okay, G.; Ertan, M.; Tozkoparan, B.; Eur. J. Med. Chem. 2012, 57, 398.

10. Kumar, K.; Sagar, S.; Esau, L.; Kaur, M.; Kumar, V.; Eur. J. Med. Chem. 2012, 58, 153.

11. He, Y.-W.; Dong, C.-Z.; Zhao, J.-Y.; Ma, L.-L.; Aisa, H. A.; Eur. J. Med. Chem. 2014, 76, 245.

12. Silva, B. N. M.; Silva, B. V.; Silva, F. C.; Gonzaga, D. T. G.; Ferreira, V. F.; Pinto, A. C.; J. Braz. Chem. Soc. 2013, 24, 179.

13. Luche, J. L.; Synthetic Organic Sonochemistry; Plenum Press: New York, 1998.

14. Mason, T. J.; Peters, D.; Practical Sonochemistry. Power Ultrasound Uses and Applications, $2^{\text {nd }}$ ed.; Ellis Horwood: New York, 2002.
15. Silva, B. N. M.; Bastos, R. S.; Silva, B. V.; Pinto, A. C.; Quim. Nova 2010, 33, 2279.

16. Rostovtsev, V. V.; Green, L. G.; Fokin, V. V.; Sharpless, K. B.; Angew. Chem., Int. Ed. Engl. 2002, 41, 2596.

17. Kolb, H. C.; Finn, M. G.; Sharpless, K. B.; Angew. Chem., Int. Ed. Engl. 2001, 11, 2004.

18. Shao, C.; Wang, X.; Zhang, Q.; Luo, S.; Zhao, J.; Hu, Y.; J. Org. Chem. 2011, 76, 6832.

19. Pokhrel, N.; Vabbina, P. K.; Pala, N.; Ultrason. Sonochem. 2016, 29, 104.

20. Mason, T. J.; Ultrason. Sonochem. 2015, 25, 89.

21. Mason, T. J.; Lorimer, J. P.; Sonochemistry (Theory, Applications and Uses of Ultrasound in Chemistry); Ellis Horwood Limited: Chichester, and John Wiley and Sons: New York, 1988.

22. Ashokkumar, M.; Lee, J.; Kentish, S.; Grieser, F.; Ultrason. Sonochem. 2007, 14, 470.

23. Bastide, J.; Henri-Rousseau, O. In The Chemistry of the Carbon-Carbon Triple Bond, $5^{\text {th }}$ ed.; Patai, S., ed.; Interscience Publishers: London, 1978, p. 447-552.

24. Molander, G. A.; Ham, J.; J. Org. Lett. 2006, 8, 2767.

25. Feldman, A. K.; Colasson, B.; Sharpless, K. B.; Fokin, V. V.; J. Am. Chem. Soc. 2005, 127, 13444.

Submitted: February 5, 2016

Published online: April 19, 2016 